\title{
Pulmonary Artery Dilatation Is a Common Finding in a Coronary Artery CT Angiography Population
}

\author{
S. PETTERI KAUHANEN ${ }^{1,2}$, TIMO LIIMATAINEN ${ }^{3,4}$, MIIKA KORHONEN $^{2}$, JOHANNES PARKKONEN $^{1}$, \\ JUSKA VIENONEN ${ }^{1}$, RITVA VANNINEN ${ }^{1,2}$ and MARJA HEDMAN ${ }^{2,5,6}$ \\ ${ }^{1}$ School of Medicine, Clinical Radiology, University of Eastern Finland, Kuopio, Finland; \\ ${ }^{2}$ Department of Clinical Radiology, Kuopio University Hospital, Clinical Imaging Center, Kuopio, Finland; \\ ${ }^{3}$ Research Unit of Medical Imaging, Physics and Technology, University of Oulu, Oulu, Finland; \\ ${ }^{4}$ Department of Diagnostic Radiology, Oulu University Hospital, Oulu, Finland; \\ ${ }^{5}$ Department of Cardiothoracic Surgery, Heart Center, Kuopio University Hospital, Kuopio, Finland; \\ ${ }^{6}$ Institute of Clinical Medicine, University of Eastern Finland, Kuopio, Finland
}

\begin{abstract}
Background/Aim: Dilatation of the main pulmonary artery (mPA) is a common incidental finding in chest imaging and often leads to consultation. The aim of this study was to determine the prevalence of $\mathrm{mPA}$ dilatation in a coronary artery CT angiography (CCTA) population. Patients and Methods: The study investigated 985 consecutive patients scheduled for diagnostic CCTA. The transverse axial diameter of the MPA was measured. The prevalence of $M P A$ dilatation was estimated using different reference values (Framingham Heart Study: 28.9 $\mathrm{mm}$ for males and $26.9 \mathrm{~mm}$ for females, Bozlar: $29.5 \mathrm{~mm}$ for both genders and Karazincir: $32.6 \mathrm{~mm}$ for males and $31.9 \mathrm{~mm}$ for females). Results: The patient mean age was $53.0 \pm 9.7$ years $(66.5 \%$ were women). Body surface area (BSA) correlated moderately with the $\mathrm{MPA}$ diameter $(r=0.423, p<0.001)$. The prevalence of $m P A$ dilatation varied from $5.9 \%$ (Karazincir) to $33.7 \%$ (Framingham Heart Study) in the overall study population. Conclusion: The prevalence of $M P A$ dilatation is high in a CCTA patient population when using a cut-off value from the Framingham Heart Study.
\end{abstract}

Pulmonary hypertension, caused either by primary pulmonary artery hypertension or by secondary reasons, such as chronic thromboembolic disease, is the most

This article is freely accessible online.

Correspondence to: S. Petteri Kauhanen, BM, School of Medicine, Clinical Radiology, University of Eastern Finland, P.O. Box 100, FI-70029, KYS, Finland. Tel: +358 447176959, e-mail: petteri.kauhanen@student.uef.fi

Key Words: Dilatation, CT-angiography, pulmonary artery, prevalence. common cause behind main pulmonary artery (mPA) dilatation (1). Dilatation of the mPA is a common incidental finding in chest imaging and often leads to medical consultation (1-3). Significant mPA dilatation may result in life-threatening complications, such as rupture or dissection of the mPA, which can lead to a critical cardiac tamponade (4). In addition, an aneurysmal dilatation may compress intrathoracic structures such as the left main coronary artery, pulmonary veins, the main bronchi, or recurrent laryngeal nerves. Regardless of the possibly fatal complications, standardized treatment options are not well established for the mPA aneurysms, pseudo-aneurysms and dissection (4).

The relationship between the mPA diameters and body surface area (BSA) has been demonstrated in several studies (5-7). The association between the mPA and ascending aortic (AA) diameters has been examined for the prediction of pulmonary arterial (PA) pressure $(8,9)$. $\mathrm{Ng}$ et al. reported that a ratio of mPA to AA diameter greater than 1 is associated with a mean PA pressure of $20 \mathrm{mmHg}$ or higher, with a sensitivity of $70 \%$, a specificity of $92 \%$, and a positive predictive value of $96 \%$ (10). Case reports of patients with both $\mathrm{mPA}$ and AA dilatation have been published $(11,12)$.

Nonetheless, studies of the prevalence of mPA dilatation are scarce. Our main purpose was to evaluate the prevalence of mPA dilatation in a coronary artery CT angiography (CCTA) population where mPA dilatation is a common incidental finding, especially when the diagnostics of coronary artery disease (CAD) has lately shifted towards CCTA according to ESC 2019 guidelines (13). The other purposes were to compare the published reference values for mPA dilatation in our population and to evaluate the associations between mPA and AA dilatation and identify predisposing risk factors for mPA dilatation. 


\section{Patients and Methods}

The study was approved by the Ethics Committee of the Hospital District of Northern Savo and it follows the rules of Declaration of Helsinki. CCTA imaging was performed on the basis of clinical indications; thus, the patients were not exposed to additional radiation and patients' clinical treatment was unaffected by this retrospective study. The population of the present study has also been evaluated in prior publications (14-16).

Study population. This retrospective study examined 1065 consecutive patients with a low-to-moderate pretest probability for CAD who had been imaged with CCTA between January 2012 and March 2018 in Kuopio University Hospital. Seventy-nine patients were excluded due to motion artefacts or inadequate visibility of $\mathrm{mPA}$ or AA in CCTA and one patient due to age under 16 years. Thus, the final study population was 985 patients.

Risk factors for cardiovascular diseases as well as other characteristics were collected from the medical records for all patients. Details of the definition of the cardiovascular risk factors have been described in a prior study (15). The CCTA interpretation had been done by imaging cardiologists or cardiac radiologists with over 6 years of experience in cardiac imaging.

Pulmonary diseases (asthma, chronic obstructive pulmonary disease (COPD), pulmonary fibrosis and acute or chronic pulmonary embolism) were collected from the medical records for 100 patients having the largest mPA diameters. In addition, further diagnostic tests and other clinical consequences after CCTA were registered for these patients

Height and weight at the time of CCTA were available for 732 patients. Obesity was determined when BMI was greater than or equal to $30 \mathrm{~kg} / \mathrm{m}^{2}$ and overweight when BMI was greater than or equal to $25 \mathrm{~kg} / \mathrm{m}^{2}$. To obtain body size adjusted values for mPA diameter, an mPA size index (mPASI), determined as the ratio of mPA diameter and BSA, was calculated for further analysis.

CCTA data acquisition. CCTA imaging was performed during middiastole according to routine clinical practice using four different CT scanners capable of ECG-gated fast coronary imaging (Somatom Definition AS 64; Somatom Definition AS+ 128; Definition Edge; Definition Flash, Siemens Medical Solutions, Erlangen, Germany). The patients were scanned in the supine position with their hands above their head to avoid artefacts. The tube voltage, varying between 80 and $120 \mathrm{kV}$, was adjusted according to the patient's size. The image area extended from the tracheal bifurcation to the inferior cardiac apex. The in-plane resolution was $512 \times 512$ pixels, with z-axis coverage including the area from the bifurcation to the diaphragm. The heart rate was optimized to be below 65 beats/minute by administering 5 $20 \mathrm{mg}$ metoprolol succinate (Seloken $1 \mathrm{mg} / \mathrm{ml}$, Genexi, Fontenay sous Bois, France) intravenously. The detailed imaging procedure has been presented in a previous study (14).

Measurements of pulmonary artery and ascending aortic diameters. One experienced observer (SPK) retrospectively analyzed the CCTA images on an IDS7 diagnostic workstation (version 17.3.6; Sectra Imtec, Linköping, Sweden). The slice thickness was $0.6 \mathrm{~mm}$. The transverse axial diameter of the $\mathrm{mPA}$ at the level of the bifurcation of the right PA was measured (Figure 1A). The diameter of AA was assessed at the same level as the mPA perpendicular to the centerline of aorta and it was named as AAp. Additionally, the
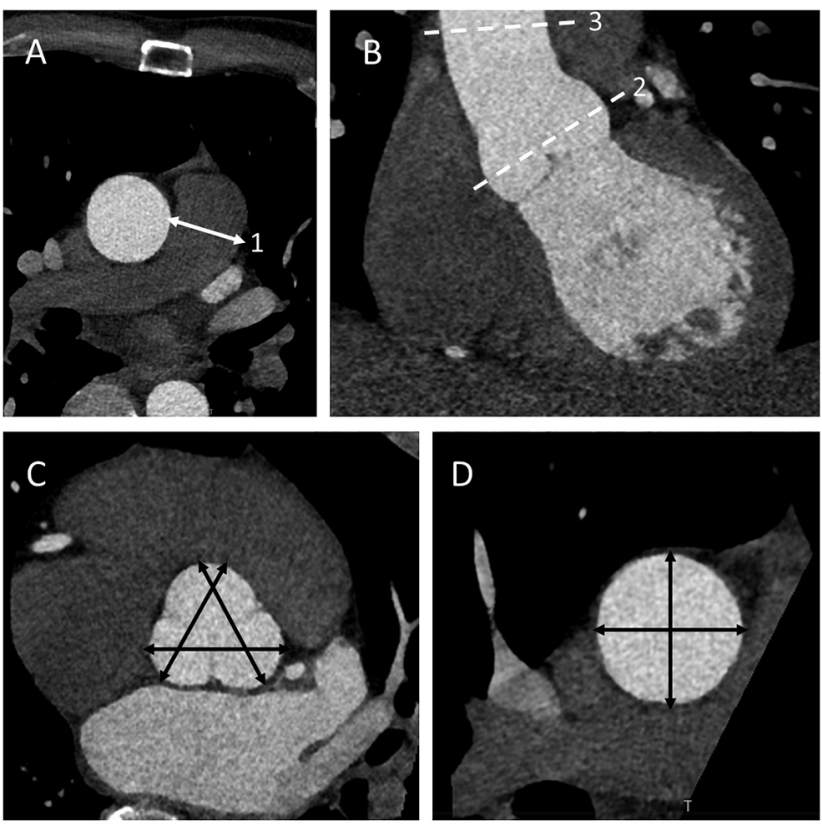

Figure 1. (A) The transverse axial diameter (1) of the MPA was measured at the level of the bifurcation of the right pulmonary artery. (B) The diameter of aortic root was measured at sinus valsalva plane (2) and the diameter of AA was measured from the outer wall to the outer wall at the same level, designated here as the MPA measurement (3) by using multiplanar reconstruction $(C-D)$.

diameter of the aortic root (AAr) was measured at the maximal sinus valsalva plane (Figure 1B-D) (17).

Reference values for $\mathrm{MPA}$ and aortic diameters. The published reference values for $\mathrm{mPA}$ diameters have been compiled in Table I according to the different imaging modalities.

Truong et al. investigated 706 healthy subjects without pulmonary or cardiovascular diseases from the Framingham Heart Study who had been imaged with non-contrast ECG gated eightslice cardiac multi-detector CT (5). The $90^{\text {th }}$ percentile cut-off value for normal mPA diameter was defined to be $28.9 \mathrm{~mm}$ for males and $26.9 \mathrm{~mm}$ for females (5).

Previously, Bozlar et al. had utilized contrast-enhanced multidetector CT to evaluate 126 healthy adults with normal thoracic CT findings and normal PA pressure. Gender was not significantly associated with $\mathrm{mPA}$ diameters $(p=0.08)$; thus, the $95^{\text {th }}$ percentile cut-off value for both genders was set to $29.5 \mathrm{~mm}$ (18).

Karazincir et al. investigated 112 patients without pulmonary pathology with contrast-enhanced chest CT. On the basis of their results, the $95 \%$ cut-off value for $\mathrm{mPA}$ diameter was set to $32.6 \mathrm{~mm}$ for males and $31.9 \mathrm{~mm}$ for females (6).

The reference values for normal AA, in terms, according to the European Society of Cardiology (ESC) guidelines for aortic diseases (2014) have been set to be less than $40 \mathrm{~mm}$ at the AAr and AAp levels (17).

Statistical analysis. The normality of the mPA diameter data was analyzed by using the Kolmogorov-Smirnov test. Since parameters 





with a skewed distribution (association between mPA diameter and cardiovascular risk factors) were tested with the Mann-Whitney $U$ test and the results are presented as median values with interquartile range (IQR).

Correlations between the mPA diameters and continuous scaled parameters were tested by the Spearman correlation test. Multivariate logistic regression analysis was used to test the relationship between mPA diameter and cardiovascular risk factors. Statistical significance was set to $p<0.05$ and high statistical significance to $p<0.001$. All statistical analyses were performed by using SPSS Statistics 27 (IBM, Chicago, USA).

\section{Results}

Study population. The mean age of the patients $(n=985)$ was $53.0 \pm 9.7$ years and the majority of patients were women $(\mathrm{n}=655,66.5 \%)$. Most patients $(87.5 \%)$ had at least one cardiovascular risk factor. Detailed characteristics of the study population as well as mean values of mPA and AA diameters and PA/AA-ratio are shown in Table II. Illustrative cases of mPA and AA dilatation are presented in Figure 2.

Prevalence of $m P A$ dilatation. According to the cut-off values published by Truong et al. (Framingham Heart Study), the overall prevalence of mPA dilatation was as high as $33.7 \%$ (34.8\% in males and $33.1 \%$ in females). On the other hand, if one applies the cut-off values published by Bozlar et al., then our overall prevalence of mPA dilatation would be lower; $18.1 \%$ (29.1\% in males and $12.5 \%$ in females). When using the cut-off values published by Karazincir et al., the overall prevalence of mPA dilatation was as low as $5.9 \%$. (9.4\% in males and $4.1 \%$ in females). The prevalence of the mPA dilatation according to these different reference values are presented in Figure 3. The overall prevalence of AA dilatation was $22.5 \%$, being as high as $52.7 \%$ in males but only $7.8 \%$ in females according to ESC guidelines for aortic diseases.

Factors correlating to mPA diameter. Of the 100 patients having the largest mPA diameters (range=31.2 mm-44.1 $\mathrm{mm}), 14$ (14\%) had asthma, 3 (3\%) had suffered prior pulmonary embolism, 1 (1\%) had COPD and 1 (1\%) had pulmonary fibrosis. In the present study, the presence of pulmonary diseases did not associate significantly $(p>0.05)$ with larger mPA diameters.

The diameter of mPA correlated significantly with BSA $(\mathrm{r}=0.423, p<0.001)$. Significant correlations were also found with weight $(\mathrm{r}=0.418, p<0.001)$, height $(\mathrm{r}=0.286, p<0.001)$, and BMI $(\mathrm{r}=0.325, p<0.001)$. The age of the patient did not correlate with the mPA diameter $(\mathrm{r}=-0.020, p=0.537)$ but correlated rather weakly with body size-adjusted mPASI values $(\mathrm{r}=0.245, p<0.001)$.

In Table III, the factors which independently associated with the mPA diameter, mPASI and PA/AA-ratio, are
Table II. Detailed characteristics of the study population.

\begin{tabular}{lccc}
\hline & $\begin{array}{c}\text { All patients } \\
\mathrm{n}=985\end{array}$ & $\begin{array}{c}\text { Males } \\
\mathrm{n}=330\end{array}$ & $\begin{array}{c}\text { Females } \\
\mathrm{n}=655\end{array}$ \\
& mean $\pm \mathrm{SD}$ & mean $\pm \mathrm{SD}$ & $\mathrm{mean} \pm \mathrm{SD}$ \\
\hline Age (years) & $53.0 \pm 9.7$ & $48.7 \pm 10.5$ & $55.1 \pm 8.5$ \\
BMI (kg/m2) & $28.1 \pm 5.3$ & $28.7 \pm 4.7$ & $27.7 \pm 5.5$ \\
BSA (m2) & $1.9 \pm 0.2$ & $2.1 \pm 0.2$ & $1.8 \pm 0.2$ \\
Height $(\mathrm{cm})$ & $168.7 \pm 9.6$ & $178.3 \pm 6.4$ & $163.6 \pm 6.6$ \\
Weight $(\mathrm{kg})$ & $80.2 \pm 17.7$ & $90.8 \pm 16.2$ & $74.3 \pm 15.6$ \\
AAp diameter (mm) & $33.7 \pm 4.5$ & $35.3 \pm 4.8$ & $32.9 \pm 4.2$ \\
AAr diameter (mm) & $36.6 \pm 4.6$ & $40.2 \pm 4.4$ & $34.7 \pm 3.5$ \\
mPA diameter (mm) & $26.5 \pm 3.7$ & $28.0 \pm 3.7$ & $25.8 \pm 3.4$ \\
PA/AA-ratio & $0.79 \pm 0.11$ & $0.80 \pm 0.11$ & $0.79 \pm 0.11$ \\
\hline & $\mathrm{n}(\%)$ & $\mathrm{n}(\%)$ & $\mathrm{n}(\%)$ \\
\hline Bicuspid aortic valve & $29(2.9)$ & $22(6.7)$ & $7(1.1)$ \\
CAD & $372(37.8)$ & $153(46.4)$ & $219(33.4)$ \\
Diabetes & $80(8.1)$ & $30(9.1)$ & $50(7.6)$ \\
Hypercholesterolemia & $496(50.4)$ & $158(47.9)$ & $338(51.6)$ \\
Hypertension & $450(45.7)$ & $142(43.0)$ & $308(47.0)$ \\
Mechanical aortic valve & $1(0.1)$ & 0 & $1(0.2)$ \\
Positive family history & $565(57.4)$ & $167(50.6)$ & $398(60.8)$ \\
for CAD & & & \\
Smoking & $253(25.7)$ & $123(37.3)$ & $130(19.8)$ \\
\hline & & & \\
& & &
\end{tabular}

AAp, Ascending aorta at level of main pulmonary artery; AAr, ascending aortic root; BMI, body mass index; BSA, body surface area; $\mathrm{CAD}$, coronary artery disease; $\mathrm{mPA}$, main pulmonary artery. Smoking determined as patients who still smoked regularly or had stopped $<30$ years in the past.

presented. When testing these factors with multivariate regression analysis, only $\mathrm{CAD}(\mathrm{B}=0.6 \mathrm{~mm}, p=0.016)$, male gender $(B=1.9 \mathrm{~mm}, p<0.001)$ and obesity $(B=1.7 \mathrm{~mm}$, $p<0.001)$ associated with the larger mPA diameters whereas positive family history for CAD ( $\mathrm{B}=-0.8 \mathrm{~mm}, p=0.004)$ associated with the smaller diameter of the mPA.

$m P A$ diameters in a 'healthy' subpopulation. From the total study population $(n=985)$, we selected for further analyses a 'healthy' subgroup with (1) no CAD (no signs of over $50 \%$ stenosis or coronary calcification) in CCTA, (2) nonsmokers, and (3) not overweight. The size of this 'healthy' subgroup was 103 patients and the mean age was $52.1 \pm 9.9$ years with the majority being females $(n=83,78.3 \%)$. The mean mPA diameter was $24.6 \pm 3.6 \mathrm{~mm}$, being $26.8 \pm 4.7 \mathrm{~mm}$ in males and $24.0 \pm 3.1 \mathrm{~mm}$ in females. In this 'healthy' subpopulation, the overall prevalence of mPA dilatation was $18.9 \%$ when using the cut-off values devised by Truong et al., i.e., almost three times higher than when using the cutoff values by Bozlar et al. (6.6\%), and almost ten times higher than when using the cut-off values supplied by Karazincir et al. (1.9\%). 


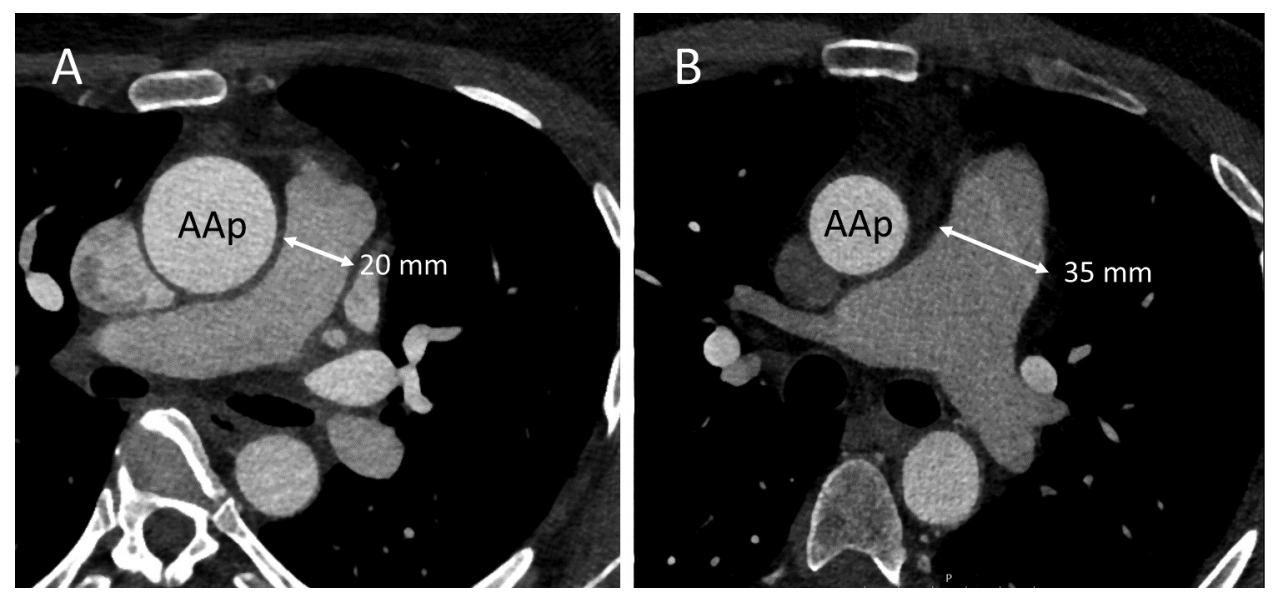

Figure 2. Illustrative images of two patient cases. Aortic diameters were measured with multiplanar reconstruction perpendicular to the centerline of the vessel. (A) A 47-year-old female. The diameter of the ascending aorta at the level of pulmonary artery (AAp) is larger (37 mm) than the diameter of the main pulmonary artery ( $\mathrm{mPA}, 20 \mathrm{~mm})$. At the aortic root (AAr), the diameter is $34 \mathrm{~mm}$. (B) A 52-year-old male. The diameter of the $\mathrm{mPA}(35 \mathrm{~mm})$ clearly exceeds that of the AAp $(30 \mathrm{~mm})$ and can be considered as dilated according to the reference values (5). The diameter of the AAr was $39 \mathrm{~mm}$.

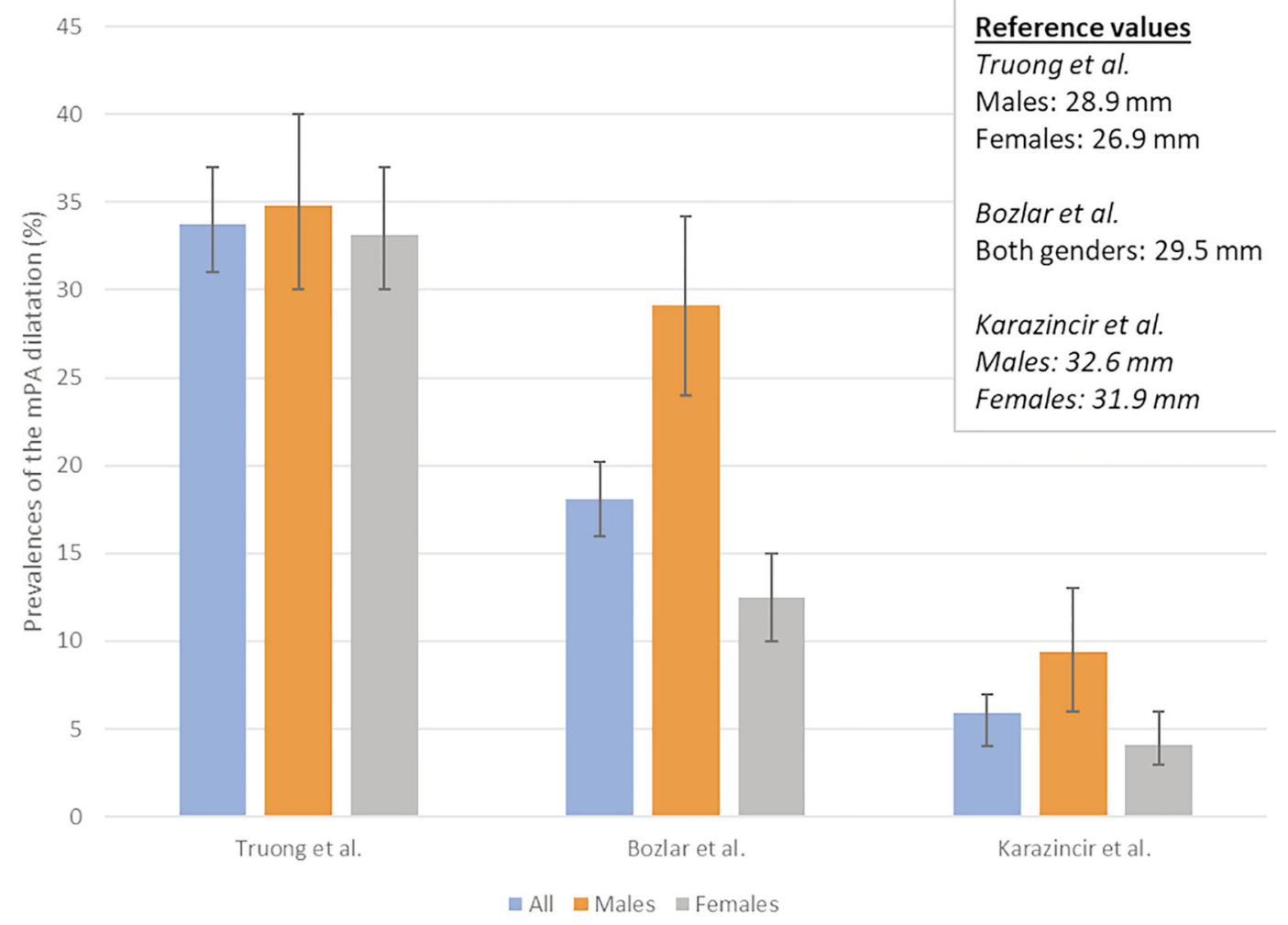

Figure 3. Prevalence of the main pulmonary artery ( $m P A)$ dilatation according to different reference values published in the literature.

The relationship between $\mathrm{mPA}$ and $A A$ diameters. The diameter of mPA correlated moderately with the AAp diameter $(r=0.461$, $p<0.001)$ and with the AAr diameter $(\mathrm{r}=0.486, p<0.001)$. The body size adjusted mPA diameter, mPASI, correlated only weakly with the AA diameter $(\mathrm{r}=0.178, p<0.001)$. Patients with dilated AA according to the ESC guidelines had also larger mPA diameters (mean $28.6 \mathrm{~mm}$, IQR 26.5-31.5 mm) than the patients with normal AA (mean $25.6 \mathrm{~mm}$, IQR 23.5-27.9 mm, $p<0.001$ ). 
in vivo $35: 2177-2185(2021)$

Table III. Risk factors for increased diameter of the main pulmonary artery (mPA). The main pulmonary artery size index (mPASI) was determined as the ratio of $\mathrm{mPA}$ diameter to body surface area. The PA/AA-ratio was determined as the ratio of $m P A$ diameter and ascending aortic diameter.

\begin{tabular}{|c|c|c|c|c|c|c|}
\hline & $\begin{array}{c}\mathrm{mPA}(\mathrm{mm}) \\
\text { median (interquartile range) }\end{array}$ & $p$-Value & $\begin{array}{c}\text { mPASI } \\
\text { median (interquartile range) }\end{array}$ & $p$-Value & $\begin{array}{c}\text { PA/AA-ratio } \\
\text { median (interquartile range) }\end{array}$ & $p$-Value \\
\hline \multicolumn{7}{|c|}{ AA dilatation } \\
\hline Present & $28.6(26.5-31.5)$ & \multirow[t]{2}{*}{$<0.001$} & $13.6(12.6-15.4)$ & \multirow[t]{2}{*}{0.703} & $0.77(0.69-0.84)$ & \multirow[t]{2}{*}{$<0.001$} \\
\hline Absent & $25.6(23.5-27.9)$ & & $13.7(12.5-15.0)$ & & $0.80(0.72-0.86)$ & \\
\hline \multicolumn{7}{|l|}{ BAV } \\
\hline Present & $27.3(24.5-31.0)$ & \multirow[t]{2}{*}{0.093} & $13.6(12.5-15.3)$ & \multirow[t]{2}{*}{0.983} & $0.69(0.59-0.83)$ & \multirow[t]{2}{*}{0.002} \\
\hline Absent & $26.2(24.0-28.6)$ & & $13.7(12.5-15.1)$ & & $0.79(0.72-0.86)$ & \\
\hline \multicolumn{7}{|l|}{ CAD } \\
\hline Present & $26.8(24.6-29.0)$ & \multirow[t]{2}{*}{$<0.001$} & $14.0(12.6-15.5)$ & \multirow[t]{2}{*}{0.016} & $0.78(0.72-0.85)$ & \multirow[t]{2}{*}{0.044} \\
\hline Absent & $25.8(23.8-28.4)$ & & $13.4(12.5-14.9)$ & & $0.80(0.71-0.87)$ & \\
\hline \multicolumn{7}{|l|}{ Diabetes } \\
\hline Present & $27.8(24.7-29.9)$ & \multirow[t]{2}{*}{0.005} & $13.5(11.8-15.1)$ & \multirow[t]{2}{*}{0.299} & $0.79(0.73-0.90)$ & \multirow[t]{2}{*}{0.313} \\
\hline Absent & $26.1(24.0-28.6)$ & & $13.7(12.6-15.1)$ & & $0.79(0.72-0.86)$ & \\
\hline \multicolumn{7}{|l|}{ Gender } \\
\hline Male & $27.7(25.4-30.0)$ & \multirow[t]{2}{*}{$<0.001$} & $13.0(12.0-14.3)$ & \multirow[t]{2}{*}{$<0.001$} & $0.80(0.72-0.87)$ & \multirow[t]{2}{*}{0.119} \\
\hline Female & $25.6(23.5-27.9)$ & & $14.0(12.8-15.4)$ & & $0.79(0.72-0.86)$ & \\
\hline \multicolumn{7}{|c|}{ Hypercholesterolemia } \\
\hline Present & $26.1(24.0-28.5)$ & \multirow[t]{2}{*}{0.518} & $13.9(12.6-15.2)$ & \multirow[t]{2}{*}{0.220} & $0.78(0.71-0.85)$ & \multirow[t]{2}{*}{0.006} \\
\hline Absent & $26.4(24.0-28.8)$ & & $13.6(12.4-15.0)$ & & $0.80(0.73-0.87)$ & \\
\hline \multicolumn{7}{|c|}{ Hypertension } \\
\hline Present & $26.5(24.1-29.0)$ & \multirow[t]{2}{*}{0.015} & $13.6(12.5-14.9)$ & \multirow[t]{2}{*}{0.288} & $0.78(0.72-0.85)$ & \multirow[t]{2}{*}{0.023} \\
\hline Absent & $25.8(24.0-28.4)$ & & $13.8(12.6-15.3)$ & & $0.80(0.72-0.87)$ & \\
\hline \multicolumn{7}{|c|}{$\begin{array}{l}\text { Positive family history } \\
\text { for CAD }\end{array}$} \\
\hline Present & $26.0(23.9-28.4)$ & \multirow[t]{2}{*}{0.014} & $13.6(12.5-15.0)$ & 0.218 & $0.79(0.71-0.86)$ & 0.208 \\
\hline Absent & $26.6(24.4-29.1)$ & & $13.8(12.6-15.3)$ & & $0.79(0.72-0.87)$ & \\
\hline Obesity & & & & & & \\
\hline Present & $27.9(25.2-30.0)$ & $<0.001$ & $12.9(11.8-14.4)$ & $<0.001$ & $0.81(0.73-0.87)$ & 0.002 \\
\hline Absent & $25.7(23.7-28.2)$ & & $14.0(12.9-15.4)$ & & $0.78(0.71-0.85)$ & \\
\hline Smoking & & & & & & \\
\hline Present & $26.5(24.3-28.8)$ & 0.240 & $13.2(12.2-14.6)$ & $<0.001$ & $0.79(0.73-0.86)$ & 0.805 \\
\hline Absent & $26.1(23.9-28.7)$ & & $13.9(12.7-15.3)$ & & $0.79(0.72-0.86)$ & \\
\hline
\end{tabular}

AA, Ascending aorta; BAV, bicuspid aortic valve; CAD, coronary artery disease.

However, AA dilatation was not associated with greater mPASI values when adjusted for the body size $(p>0.05)$.

Clinical consequences of the diagnosis of mPA dilatation. Among the 100 patients having the largest mPA diameters, the diagnosis of mPA dilatation did not lead to any clinical consequences in 94 patients (94\%). However, mPA dilatation led to additional imaging in 4 patients (cardiac MRI for 3 patients and pulmonary high-resolution CT for one patient). As a result of these subsequent diagnostic imaging, one ventricular septum defect closure and one percutaneous coiling of pulmonary arteriovenous malformation were performed.

\section{Discussion}

The key finding of the present study was that pulmonary artery dilatation is a frequent incidental finding when examining a consecutive population undergoing CCTA. A relatively high number of our patients had one or more risk factors for cardiovascular diseases, therefore, the study population could not be considered as a healthy population. However, the patients were relatively healthy with regard to pulmonary diseases. In general, this population represents well a real-life patient population in which the diagnosis of mPA dilatation is made incidentally. Since the diagnostics of CAD has lately shifted towards CCTA, this study provides valuable information for the daily clinical work.

The published mPA reference values can be divided according to the imaging modality that has been used (Table I). Truong et al. described reference values for mPA dilatation in the so far largest study population consisting of 700 middle-aged Americans (Framingham Heart Study) (5) who were healthy with respect to pulmonary and cardiovascular diseases. In the report of Gallego et al., the prevalence of mPA dilatation was studied with CT in patients 
with congenital heart disease and the prevalence of mPA dilatation in that population was $18 \%$ when using an upper limit of $29 \mathrm{~mm}$ for both genders (19). The number of reference values obtained with CT imaging is highest in the published data $(5,6,18,20)$ including both contrast enhanced $(6,18)$ and non-enhanced $(5,20)$ CT studies. In addition, reference values obtained with MRI (7) and ultrasound imaging (21) have been published. We selected the reference values based on $\mathrm{CT}$ imaging studies so that they would be comparable with our own CT based data.

According to the best of our knowledge, the prevalence of mPA dilatation has not been widely studied. According to the reference values adapted from the Framingham Heart Study, the prevalence of mPA dilatation was high, present in approximately every third patient in our study population. One can speculate that there may be several factors explaining this high prevalence. One of the possible factors is the size of the patient. In our study, the diameter of mPA correlated significantly with BMI, height and especially BSA, paralleling the results of several previously published studies (5-7). In the study of Truong et al., the healthy subgroup did not include overweight patients. In our 'healthy' subgroup of patients with normal weight, the prevalence of mPA dilatation was only $19 \%$. The prevalence of mPA dilatation was smaller if we applied the reference values published by Bozlar et al. (18) and Karazincir et al. (6) in smaller study populations based on Turkish citizens. It must also be noted that the traditional method to measure the cut-off values is mean \pm 2 SD (95\%) (22) while the results in the study by Truong et al. are given as $90 \%$ percentiles. Obviously, the $95 \%$ cutoff value seems to be reasonable if one wishes to avoid over-diagnosis. Additionally, the method of measuring the mPA diameter is crucial for reproducibility. Most typical method is to measure the diameter from the transverse axial slice at the level of the bifurcation of the right $\mathrm{PA}$ (5).

The relationship between $\mathrm{mPA}$ and aortic diameter has been mainly studied by calculating the PA/AA-ratio for the prediction of pulmonary pressure $(8,9)$. However, certain genetic syndromes such as Marfan syndrome predispose to both aortic and PA dilatation (23). We have previously shown a high prevalence of AA dilatation in this same population (15). The present study detected a positive correlation between the mPA and AA diameters. It is obvious that the larger main vessel diameters were evident in patients with larger BSAs, in other words, both aorta and pulmonary arteries are larger in patients with a greater body size. However, if there is a disease behind the mPA dilatation, this correlation may no longer be valid.

It is well recognized that obesity results in elevated PA pressure (24) and mPA dilatation, thus becoming increasingly recognized as an independent risk factor for mPA dilatation. The significantly increased PA/AA-ratio found here supports this suggestion. Several mechanisms have been postulated to cause pulmonary hypertension in obese patients e.g., obstructive sleep apnea, obesity hypoventilation syndrome and obesity cardiomyopathy (25).

It is known that pulmonary hypertension with different etiologies is the most common cause of mPA dilatation. COPD is a common cause for pulmonary hypertension; this disease is mainly induced by smoking, pulmonary fibrosis and embolism (26). However, in our study only one patient among the 100 patients having the largest mPA diameters had COPD while 14 had asthma. Thus, the present study population was relatively healthy regarding pulmonary diseases. One fourth of our patients were smokers but smoking was not associated with mPA dilatation. It could be speculated that since the patients were rather young, smoking might not yet have progressed to COPD and had not seriously affected in pulmonary pressure.

Our study also investigated the cardiovascular risk factors or possible predictive issues associating with mPA dilatation. Previously, hypertension, diabetes and CAD have been reported to associate with increased mPA diameter (5). However, in the multivariate regression analysis, only CAD, male gender and obesity associated with the increased mPA diameter, which might indicate that after all the patient's body size is the most affecting factor. Left ventricular systolic and diastolic dysfunction can lead to mPA dilatation. Both of these conditions can be caused by CAD (26). In the present study, approximately $40 \%$ of the patients had been diagnosed with CAD. It is well-known that CAD associates with high mortality and morbidity rates and its prevention is crucial (27).

One of the main limitations of this retrospective study was the limited data of patient lung capacity and underlying pulmonary diseases. Since all the factors that influence in ventilation can have an impact on pulmonary circulation, perfusion and vascular resistance, they also can have a high impact on the diameter of the mPA. Another limitation is that the reproducibility of our mPA measurements was not assessed. However, the reproducibility of the method has been reported to be excellent in previous studies $(5,6)$, and the reproducibility of the AA measurements have been shown to be excellent in a previous MRI study (28). A high number of patients had risk factors for cardiovascular diseases, thus the prevalence of mPA dilatation is higher than in the healthy population. However, examined population represents that clinical population where mPA dilatation diagnosis is usually done.

In conclusion, the prevalence of mPA dilatation proved to be high in a consecutive CCTA population. Every third patient had dilated mPA when using the current clinical reference values adopted from the Framingham Heart Study. The diameter of mPA correlated strongly with BSA suggesting that it would be reasonable to use body size- 
adjusted reference values in clinical practice. In the present study population, the clinical impact of the observed mPA dilatation was low and led rarely to clinical interventions. In the future, the increasing number of patients scheduled for CCTA makes it important to accurately identify those patients with mPA dilatation of clinical significance.

\section{Conflicts of Interest}

The Authors have no conflicts of interest.

\section{Authors' Contributions}

SPK: Study conception, data acquisition, data analysis, data interpretation, drafting and writing manuscript. TL: Study conception, data interpretation and manuscript review. MK: Data acquisition. JP: Data acquisition. JV: Data acquisition. RV: Study conception, data interpretation and manuscript review. MH: Study conception, data interpretation and manuscript review and writing.

\section{Acknowledgements}

This study has received funding by Instrumentarium Science Foundation (SPK).

\section{References}

1 Raymond TE, Khabbaza JE, Yadav $\mathrm{R}$ and Tonelli AR: Significance of main pulmonary artery dilation on imaging studies. Ann Am Thorac Soc 11(10): 1623-1632, 2014. PMID: 25406836. DOI: 10.1513/AnnalsATS.201406-253PP

2 Lee J, Kirschner J, Pawa S, Wiener DE, Newman DH and Shah $\mathrm{K}$ : Computed tomography use in the adult emergency department of an academic urban hospital from 2001 to 2007. Ann Emerg Med 56(6): 591-596, 2010. PMID: 20619935. DOI: 10.1016/j.annemergmed.2010.05.027

3 Wittram C, Meehan MJ, Halpern EF, Shepard JA, McLoud TC and Thrall JH: Trends in thoracic radiology over a decade at a large academic medical center. J Thorac Imaging 19(3): 164-170, 2004. PMID: 15273612. DOI: 10.1097/01.rti.000011 7623.02841.e6

4 Galiè N, Humbert M, Vachiery JL, Gibbs S, Lang I, Torbicki A, Simonneau G, Peacock A, Vonk Noordegraaf A, Beghetti M, Ghofrani A, Gomez Sanchez MA, Hansmann G, Klepetko W, Lancellotti P, Matucci M, McDonagh T, Pierard LA, Trindade PT, Zompatori M, Hoeper M and ESC Scientific Document Group: 2015 ESC/ERS Guidelines for the diagnosis and treatment of pulmonary hypertension: the joint task force for the diagnosis and treatment of pulmonary hypertension of the European Society of Cardiology (ESC) and the European Respiratory Society (ERS): endorsed by: Association for European Paediatric and Congenital Cardiology (AEPC), International Society for Heart and Lung Transplantation (ISHLT). Eur Heart J 37(1): 67-119, 2016. PMID: 26320113. DOI: 10.1093/eurheartj/ehv317

5 Truong QA, Massaro JM, Rogers IS, Mahabadi AA, Kriegel MF, Fox CS, O'Donnell CJ and Hoffmann U: Reference values for normal pulmonary artery dimensions by noncontrast cardiac computed tomography: the Framingham Heart Study. Circ Cardiovasc Imaging 5(1): 147-154, 2012. PMID: 22178898. DOI: 10.1161/CIRCIMAGING.111.968610

6 Karazincir S, Balci A, Seyfeli E, Akoğlu S, Babayiğit C, Akgül F, Yalçin F and Eğilmez E: CT assessment of main pulmonary artery diameter. Diagn Interv Radiol 14(2): 72-74, 2008. PMID: 18553279.

7 Burman ED, Keegan J and Kilner PJ: Pulmonary artery diameters, cross sectional areas and area changes measured by cine cardiovascular magnetic resonance in healthy volunteers. J Cardiovasc Magn Reson 18: 12, 2016. PMID: 26940894. DOI: 10.1186/s12968-016-0230-9

8 Kuriyama K, Gamsu G, Stern RG, Cann CE, Herfkens RJ and Brundage BH: CT-determined pulmonary artery diameters in predicting pulmonary hypertension. Invest Radiol 19(1): 16-22, 1984. PMID: 6706516. DOI: 10.1097/00004424-19840100000005

9 Mahammedi A, Oshmyansky A, Hassoun PM, Thiemann DR and Siegelman SS: Pulmonary artery measurements in pulmonary hypertension: the role of computed tomography. J Thorac Imaging 28(2): 96-103, 2013. PMID: 23096163. DOI: 10.1097/RTI.0b013e318271c2eb

$10 \mathrm{Ng}$ CS, Wells AU and Padley SP: A CT sign of chronic pulmonary arterial hypertension: the ratio of main pulmonary artery to aortic diameter. J Thorac Imaging 14(4): 270-278, 1999. PMID: 10524808. DOI: 10.1097/00005382-19991000000007

11 Sughimoto K, Nakano K, Gomi A, Nakatani H, Nakamura Y and Sato A: Pulmonary artery aneurysm with ascending aortic aneurysm concomitant with bilateral bicuspid semilunar valves. Ann Thorac Surg 82(6): 2270-2272, 2006. PMID: 17126149. DOI: 10.1016/j.athoracsur.2006.04.080

12 Dyamenahalli U, Abraham B, Fontenot E, Prasad V and Imamura M: Pathologic aneurysmal dilation of the ascending aorta and dilation of the main pulmonary artery in patients with Kabuki syndrome: valve-sparing aortic root replacement. Congenit Heart Dis 2(6): 424-428, 2007. PMID: 18377436. DOI: 10.1111/j.1747-0803.2007.00136.x

13 Knuuti J, Wijns W, Saraste A, Capodanno D, Barbato E, FunckBrentano C, Prescott E, Storey RF, Deaton C, Cuisset T, Agewall S, Dickstein K, Edvardsen T, Escaned J, Gersh BJ, Svitil P, Gilard M, Hasdai D, Hatala R, Mahfoud F, Masip J, Muneretto C, Valgimigli M, Achenbach S, Bax JJ and ESC Scientific Document Group: 2019 ESC Guidelines for the diagnosis and management of chronic coronary syndromes. Eur Heart J 41(3): 407-477, 2020. PMID: 31504439. DOI: 10.1093/eurheartj/ ehz425

14 Korhonen M, Mustonen P, Hedman M, Vienonen J, Onatsu J, Vanninen R and Taina M: Left atrial appendage morphology and relative contrast agent concentration in patients undergoing coronary artery CTA. Clin Radiol 73(11): 982.e17-982.e26, 2018. PMID: 30029834. DOI: 10.1016/j.crad.2018.06.012

15 Kauhanen SP, Saari P, Jaakkola P, Korhonen M, Parkkonen J, Vienonen J, Vanninen R, Liimatainen T and Hedman M: High prevalence of ascending aortic dilatation in a consecutive coronary CT angiography patient population. Eur Radiol 30(2): 1079-1087, 2020. PMID: 31529253. DOI: 10.1007/s00330-01906433-z

16 Kauhanen SP, Liimatainen T, Kariniemi E, Korhonen M, Parkkonen J, Vienonen J, Vanninen R and Hedman M: A smaller 
heart-aorta-angle associates with ascending aortic dilatation and increases wall shear stress. Eur Radiol 30(9): 5149-5157, 2020. PMID: 32323010. DOI: 10.1007/s00330-020-06852-3

17 Erbel R, Aboyans V, Boileau C, Bossone E, Bartolomeo RD, Eggebrecht H, Evangelista A, Falk V, Frank H, Gaemperli O, Grabenwöger M, Haverich A, Iung B, Manolis AJ, Meijboom F, Nienaber CA, Roffi M, Rousseau H, Sechtem U, Sirnes PA, Allmen RS, Vrints CJ and ESC Committee for Practice Guidelines: 2014 ESC Guidelines on the diagnosis and treatment of aortic diseases: Document covering acute and chronic aortic diseases of the thoracic and abdominal aorta of the adult. The Task Force for the diagnosis and treatment of aortic diseases of the European Society of Cardiology (ESC). Eur Heart J 35(41): 2873-2926, 2014. PMID: 25173340. DOI: 10.1093/eurheartj/ ehu281

18 Bozlar U, Ors F, Deniz O, Uzun M, Gumus S, Ugurel MS, Yazar $\mathrm{F}$ and Tayfun C: Pulmonary artery diameters measured by multidetector-row computed tomography in healthy adults. Acta Radiol 48(10): 1086-1091, 2007. PMID: 17963079. DOI: $10.1080 / 02841850701545755$

19 Gallego P, Rodríguez-Puras MJ, Serrano Gotarredona P, Valverde I, Manso B, González-Calle A, Adsuar A, Cubero JM, Díaz de la Llera L, Ordoñez A and Hosseinpour AR: Prevalence and prognostic significance of pulmonary artery aneurysms in adults with congenital heart disease. Int J Cardiol 270: 120-125, 2018. PMID: 29891239. DOI: 10.1016/j.ijcard.2018.05.129

20 Edwards PD, Bull RK and Coulden R: CT measurement of main pulmonary artery diameter. Br J Radiol 71(850): 1018-1020, 1998. PMID: 10211060. DOI: 10.1259/bjr.71.850.10211060

21 Sheikhzadeh S, De Backer J, Gorgan NR, Rybczynski M, Hillebrand M, Schüler H, Bernhardt AM, Koschyk D, Bannas P, Keyser B, Mortensen K, Radke RM, Mir TS, Kölbel T, Robinson PN, Schmidtke J, Berger J, Blankenberg S and von Kodolitsch Y: The main pulmonary artery in adults: a controlled multicenter study with assessment of echocardiographic reference values, and the frequency of dilatation and aneurysm in Marfan syndrome. Orphanet J Rare Dis 9: 203, 2014. PMID: 25491897. DOI: 10.1186/s13023-014-0203-8
22 Sharma B and Jain R: Right choice of a method for determination of cut-off values: A statistical tool for a diagnostic test. Asian Journal of Medical Sciences 5(3): 30-34, 2018. DOI: 10.3126/ajms.v5i3.9296

23 Dean JC: Marfan syndrome: clinical diagnosis and management. Eur J Hum Genet 15(7): 724-733, 2007. PMID: 17487218. DOI: 10.1038/sj.ejhg. 5201851

24 Parameswaran K, Todd DC and Soth M: Altered respiratory physiology in obesity. Can Respir J 13(4): 203-210, 2006. PMID: 16779465. DOI: 10.1155/2006/834786

25 Friedman SE and Andrus BW: Obesity and pulmonary hypertension: a review of pathophysiologic mechanisms. J Obes 2012: 505274, 2012. PMID: 22988490. DOI: 10.1155/2012/ 505274

26 Hoeper MM, Ghofrani HA, Grünig E, Klose H, Olschewski H and Rosenkranz S: Pulmonary hypertension. Dtsch Arztebl Int 114(5): 73-84, 2017. PMID: 28241922. DOI: 10.3238/arztebl. 2017.0073

27 Arnett DK, Blumenthal RS, Albert MA, Buroker AB, Goldberger ZD, Hahn EJ, Himmelfarb CD, Khera A, LloydJones D, McEvoy JW, Michos ED, Miedema MD, Muñoz D, Smith SC Jr, Virani SS, Williams KA Sr, Yeboah J and Ziaeian B: 2019 ACC/AHA Guideline on the primary prevention of cardiovascular disease: a report of the American College of Cardiology/American Heart Association Task Force on Clinical Practice Guidelines. Circulation 140(11): e596-e646, 2019. PMID: 30879355. DOI: 10.1161/CIR.0000000000000678

28 Kauhanen SP, Hedman M, Kariniemi E, Jaakkola P, Vanninen R, Saari P and Liimatainen T: Aortic dilatation associates with flow displacement and increased circumferential wall shear stress in patients without aortic stenosis: A prospective clinical study. J Magn Reson Imaging 50(1): 136-145, 2019. PMID: 30659686. DOI: $10.1002 /$ jmri.26655

Received April 6, 2021

Revised April 15, 2021

Accepted April 19, 2021 